\title{
A NEW MEASURE OF HORIZONTAL EQUITY
}

\author{
Alan J. Auerbach \\ Kevin A. Hassett \\ Working Paper 7035 \\ http://www.nber.org/papers/w7035
NATIONAL BUREAU OF ECONOMIC RESEARCH 1050 Massachusetts Avenue
Cambridge, MA 02138
March 1999

\begin{abstract}
We thank Nancy Nicosia for careful research assistance, Andy Mitrusi for his provision of simulations based on the NBER TAXSIM Model, and the Burch Center for Tax Policy and Public Finance and AEI for research support. We also thank Jim Heckman, Louis Kaplow, John Roemer and participants in workshops at AEI, the Institute for Fiscal Studies, NYU Law School, and Georgetown Law Center for comments on earlier drafts. The views expressed in this paper are those of the authors and do not reflect those of the National Bureau of Economic Research.
\end{abstract}

(C) 1999 by Alan J. Auerbach and Kevin A. Hassett. All rights reserved. Short sections of text, not to exceed two paragraphs, may be quoted without explicit permission provided that full credit, including $\mathbb{C}$ notice, is given to the source. 
A New Measure of Horizontal Equity

Alan J. Auerbach and Kevin A. Hassett

NBER Working Paper No. 7035

March 1999

JEL No. D63, H22

\begin{abstract}
In this paper, we propose a new measure of horizontal equity that overcomes many of the shortcomings of previous proposed measures. Our starting point is the observation that a wellbehaved social welfare function need not evaluate "global" (vertical equity) differences in after-tax income using the same weights it applies to "local" (horizontal equity) differences, even though this constraint has been applied in the past. Following work on the structure of individual preferences, we show that a social welfare function can imply different preferences toward horizontal and vertical equity. Adopting the general approach to the measurement of inequality developed by Atkinson (1970), we use such a social welfare function to derive measures of inequality that are decomposable into components naturally interpreted as indices of horizontal and vertical equity. In particular, the former index measures deviations from the fundamental principle that equals be treated equally.

Finally, we apply our new measure to two tax-return data sets, evaluating the degree to which the horizontal equity of the US personal income tax has changed over time, and how horizontal equity would be altered by one version of recent proposals to do away with the so-called "marriage penalty."
\end{abstract}

\author{
Alan J. Auerbach \\ Department of Economics \\ University of California \\ Berkeley, CA 94720-3880 \\ and NBER \\ auerbach@econ.berkeley.edu
}

Kevin A. Hassett

AEI

1150 Seventeenth St. N.W.

Washington, DC 20036-4670

khassett@aei.org 
"Nothing is so firmly believed as what we least know."-Montaigne

\section{Introduction}

Among the normative foundations of modern tax systems, nothing is more contentious than the question of how much the tax code should be utilized to redistribute income. Designers of the tax code must assess potential reforms with an eye toward weighing the costs of foregone redistribution against the efficiency benefits of flatter rate schedules, but there is little agreement as to the appropriate weights to use. On the other hand, there is virtual unanimity that horizontal equity - the extent to which equals are treated equally - is a worthy goal of any tax system. Asked to choose between two otherwise identical tax systems that differed only in the extent to which pre-tax equals faced different average tax rates, most would choose the system that had the lowest "arbitrary" tax rate variation. While the measurement of vertical inequality, and the impact of the tax code on it, is relatively straightforward, a workable definition of horizontal equity has been elusive. From Musgrave (1959) on, there is general agreement that horizontal equity is important, but little agreement on quite what it is.

Much work in the past few decades has focused on the constructing and refining measures of horizontal equity. Rather than attempting to provide an exhaustive survey of this work, we will simply highlight the key issues that have arisen and that are relevant to our own work. First, there is the question of whether horizontal equity represents an independent concept in the context of a general aversion to inequality. If society is generally averse to inequality in the distribution of income, it has long been argued that horizontal equity will typically be implied by this aversion. (See, e.g. the discussion in Atkinson 1980.) Thus, measures of horizontal equity may simply represent components of overall measures of social welfare, and it is not clear why they merit independent inspection or concern. Second, and related to this first point, if one 
does impose independent criteria to assess horizontal equity that go beyond a general aversion to inequality, it is necessary to justify these criteria, which are likely to stand in conflict with the general aversion to inequality. The most common such additional criterion imposes an aversion to changes in individuals' relative standing in the income distribution, leading to measures of horizontal equity based on rank reversals (e.g. Feldstein 1976, Rosen 1978, Plotnick 1981, King 1983). This approach has been criticized on the ground that it gives undue weight to the status quo income distribution (Kaplow 1989).

Third, even if one does establish a case for an independent evaluation of horizontal equity, it is necessary to define what is meant by "equals" and what we mean when requiring that the tax system "treat equals equally." Also, because deviations from equal treatment are inevitable, we must specify how these deviations are to be evaluated. Even if one uses a simple observable measure like pretax income to classify individuals, it remains unclear where to draw the line in grouping individuals as equals. If our definition is not relevant for a comparison of two individuals whose incomes differ by a penny, then it is of limited importance and one for which a tiny change in income can induce large changes in measured horizontal equity.

In this paper, we develop a new measure of horizontal equity that derives from a general aversion to inequality in the income distribution, without any appeal to additional criteria. Our principal insight is that horizontal equity may represent a distinct and meaningful component of a general evaluation of inequality, if "global" and "local" differences in tax burden are accorded potentially different weights. We start with an analogy to individual preferences over consumption at different dates and consumption at a given date over different states of nature. While standard consumer preferences imply a link between aversion to differences in outcomes across states of nature (risk aversion) and across time (imperfect intertemporal substitution), 
various papers (e.g., Kreps and Porteus 1978, Epstein and Zin, 1989) have shown that this link may be broken by relaxing the von Neumann-Morgenstern axioms of expected utility. We show that an evaluation of the income distribution using a similar functional form can imply different preferences toward horizontal equity and vertical equity, much as flexible individual preferences have been used to distinguish between intertemporal substitution and risk aversion. Adopting the general approach to the measurement of inequality developed by Atkinson (1970), we use such a function to derive measures of inequality that are decomposable into components naturally interpreted as indices of horizontal and vertical equity. In particular, the horizontal equity index measures deviations from the fundamental principle that equals be treated equally. Finally, we apply our new measure to two tax-return data sets, evaluating the degree to which the horizontal equity of the US personal income tax has changed over time, and how horizontal equity would be altered by one version of recent proposals to do away with the so-called "marriage penalty."

\section{The Model}

As our focus here is on distributional issues, we ignore behavioral considerations and assume that each individual's income and tax payments are exogenous. ${ }^{1}$ There are a variety of standard approaches to measuring inequality in the distribution of income, and measures of horizontal and vertical equity in the literature that correspond to these alternatives approaches. For example, one recent approach develops a measure of horizontal equity based on the Gini coefficient of the post-tax income distribution (Aronson et al 1994), while another bases it measure on mean logarithmic deviations in post-tax income (Lambert and Ramos 1997). Each of these approaches imposes a specific metric for evaluating differences among individuals, and

\footnotetext{
${ }^{1}$ More generally, one might use our approach using measures of individual welfare that took account of issues of tax incidence and deadweight loss.
} 
it is unclear why one should prefer one to other or, for that matter, why still another might not be preferred. Moreover, as Atkinson (1970) emphasized, measures that do not impose much structure often are useful in a very restricted set of applications. Gini coefficients, for example, are informative in the absence of a specification of social preferences only if the underlying Lorenz curves do no cross. In his study of vertical equity, Atkinson demonstrated that a measure based on a social welfare function with explicit preferences toward inequality could significantly extend the reach of inequality inquiry. In the case of horizontal equity there are similar problems, in particular, it is difficult to chose among the various methods without access to an underlying objective function. Thus, rather than start with a metric, we start with a general specification of preferences over individual after-tax incomes, with parameters that vary with the degree of aversion to inequality that, in turn, imply a metric that is consistent with this specification of preferences.

The concept of horizontal equity is based on the idea that there are classes of individuals whom we would wish to label "equals." Thus, let us begin with the simplifying assumption that there are a finite number of income levels, say $M$, with $N_{i}$ individuals at each level. More generally, we might imagine these groups of equals as being defined by some characteristic, such as family structure, age, or region of residence. Following Atkinson (1970), we start with a flexible function based on individual after-tax incomes that imposes an aversion to inequality, say $\gamma$, among different levels of after-tax income:

$$
w=\left[\sum_{i=1}^{M} \sum_{j=1}^{N_{i}}\left(y_{i}-T_{i j}\right)^{1-\gamma}\right]^{\frac{1}{1-\gamma}}
$$


where $y_{i}$ is the before-tax income of individuals in group $i$, and $T_{i j}$ is the tax payment by the $j^{\text {th }}$ individual in group $i$.

Expression (1) has two important properties. First, it respects the Pareto principle, in that it is increasing in each person's after-tax income. Second, it is increasing with respect to any experiment that shifts income from an individual with higher after-tax income to one with lower after-tax income. Thus, it simultaneously incorporates notions of vertical equity (a wish to redistribute from the rich to the poor) and of horizontal equity (a wish to keep after-tax income equal for those with the same before-tax income). Clearly, it requires some modification if it is to give rise to an independent measure notion of horizontal equity.

The function in (1) constrains differences among individuals within any class $i$ to induce the same loss of social welfare as differences among individuals in different income classes. But if horizontal equity is to have any independent content, it seems both necessary and appropriate for attitudes to differ about these two types of inequality. Large differences among similar individuals might be viewed as intrinsically arbitrary (regardless of whether or not they resulted from intentionally "abusive" government behavior), and therefore more costly to the social fabric; or they might simply be viewed as more costly because individuals compare themselves to those with similar characteristics. This logic suggests that we replace (1) with

$$
w=\left[\sum_{i=1}^{M} N_{i}\left(\frac{1}{N_{i}} \sum_{j=1}^{N_{i}}\left(y_{i}-T_{i j}\right)^{1-\gamma}\right)^{\frac{1-\rho}{1-\gamma}}\right]^{\frac{1}{1-\rho}}
$$

where $\gamma$ now represents the inequality aversion within classes and $\rho$ the inequality aversion across classes. If $\rho=\gamma$, this reduces to expression (1). A similar functional form has been used in the literature to distinguish between preferences with respect to consumption over time and, at 
a given time, over states of nature. Just as we might wish to allow individuals to be more (or less) averse to variations in consumption over states of nature than to variations in consumption over time, we might wish to allow welfare to be more (or less) averse to the variations in aftertax income within a certain group than to variations among individuals in different groups. ${ }^{2}$

Note that while the function in (2) still respects the Pareto principle, it does violate another characteristic sometimes imposed on social welfare measures ${ }^{3}$, that a comparison of any two outcomes should depend only on the well-being of individuals who are not indifferent to the outcomes. For example, imagine that there are two income classes, two individuals in each income class, and that $\gamma>0$ and $\rho=0$ (there is no aversion to inequality across classes). That is, the function $w$ may be written:

$$
w=\left(\left(y_{1}-T_{11}\right)^{1-\gamma}+\left(y_{1}-T_{12}\right)^{1-\gamma}\right)^{\frac{1}{1-\gamma}}+\left(\left(y_{2}-T_{21}\right)^{1-\gamma}+\left(y_{2}-T_{22}\right)^{1-\gamma}\right)^{\frac{1}{1-\gamma}}
$$

Further, assume for simplicity that $y_{1}=y_{2}$ and that there are two outcomes, $A$ and $B$, between which the tax liabilities of individuals 12 and 22 do not change; let these fixed liabilities be $\bar{T}_{12}$ and $\bar{T}_{22}$, respectively. Suppose that under outcome $A, T_{11}=x>0$ and $T_{21}=0$, while under outcome $B, T_{21}=x$ and $T_{11}=0$. Consider two possible situations. In one, $\bar{T}_{12}=x$ and $\bar{T}_{22}=0$; in the other, $\bar{T}_{22}=x$ and $\bar{T}_{12}=0$. Then, in the first situation, $A$ eliminates horizontal inequity and will be preferred to $B$, while in the second case, $B$ eliminates horizontal inequity and will be preferred to $A$. That is, the relative weight given to individuals 11 and 21 will depend on the

\footnotetext{
${ }^{2}$ Although we make the analogy here to household decisions under uncertainty, our own analysis focuses exclusively on the evaluation of ex post income distributions.

${ }^{3}$ See, for example, the discussion in Roemer (1996), chapter 4.
} 
relative status of individuals 12 and 22. This dependence should not be surprising, for comparisons across and within groups are presumed to differ in their relative importance.

Having provided scope for the independent evaluation of local differences, we must now consider the issue of how to delineate groups of individuals, in this case income classes. One might wish to posit that individuals belong to a small number of quite distinct groups of "equals." But whether our measure of similarity is income or an alternative like age or location, the distribution much more closely resembles a continuum, with very small gaps between contiguous groups and very few individuals with exactly the same characteristics. Thus, if we define the preference parameter $\gamma$ as applying only to individuals with precisely the same income, it will have essentially no impact. Indeed, such a restriction seems inappropriate if our intent is to define reference groups of "similar" individuals. But, if we define a group of equals to include those with somewhat different incomes, the question remains how large that group should be, and where to place its boundaries. It would seem that any group boundary would impose an arbitrary discontinuity, with a small change in income inducing a large change in a person's membership in a particular reference group. Indeed, this discontinuity has been a problem with past approaches based on discrete groupings of income classes. However, it is also avoidable, because such unique income class definitions are unnecessary to compare each individual to others with similar income.

As an alternative, we may define an appropriate reference group for each income level, with such reference groups overlapping, rather than assigning each individual to only one income class. We define these reference groups in terms of a density, or scaling, function, $f_{i}(\cdot)$, that applies at income level $i$, defined over group distance, as measured by the difference between $y_{i}$ 
and the income of another group, say $y_{k}$. With this, we generalize (2) so that $\gamma$ applies within reference groups ${ }^{4}$ :

$$
w^{1-\rho}=\sum_{i=1}^{M}\left(\sum_{k=1}^{M} f_{i}\left(y_{k}-y_{i}\right) N_{k}\right)\left(\frac{1}{\sum_{k=1}^{M} f_{i}\left(y_{k}-y_{i}\right) N_{k}} \cdot \sum_{k=1}^{M} f_{i}\left(y_{k}-y_{i}\right) \sum_{j=1}^{N_{k}}\left(y_{k}-T_{k j}\right)^{1-\gamma}\right)^{\frac{1-\rho}{1-\gamma}}
$$

When $\rho=\gamma$, this reduces to expression (1) if the scaling functions are defined so that

$\sum_{i=1}^{M} f_{i}\left(y_{k}-y_{i}\right)=1$. Note that the summation here is over $i$, rather than $k$. That is, the sum of weights applied to each household, not to each reference group, must sum to 1 . To implement this, we define the shape of $f_{i}(\cdot)$ for each $i$, but let the sum $\sum_{k=1}^{M} f_{i}\left(y_{k}-y_{i}\right)=z_{i}$, where $z_{i}$ is unknown, and then solve for the vector $z$ so that $\sum_{i=1}^{M} f_{i}\left(y_{k}-y_{i}\right)=1 \quad \forall k$.

In our applications below, we define income classes so that $N_{k}$ is constant over $k$, and assume that $f_{i}(\cdot)$ is normally distributed, peaking at $k=i$. The smaller the standard deviation of the normal distribution, the tighter the income range used to define a reference group for those in income class $i$. Clearly, the shape of $f_{i}(\cdot)$ is not predetermined. Like the inequality aversion parameters $\rho$ and $\gamma$, it depends on political and ethical considerations. However, the spirit of the calculation would seem to rule out distributions that end abruptly, for these would be subject to the critique leveled against other measures that small changes in income could lead to large changes in measured horizontal equity.

\footnotetext{
${ }^{4}$ We also take both sides of the equation to the power 1- $\rho$ to make the expression less messy.
} 
There is a certain analogy here between the specification of the function $f_{i}(\cdot)$ to estimate horizontal equity in the neighborhood of income level $y_{i}$ and the choice of a kernel in the nonparametric estimation of the value of a function at a particular point in the function's domain. In that literature (e.g., Yatchew 1998), there is a trade-off between the extra information gained from expanding the width of the kernel and the bias associated with using information from observations that are increasingly dissimilar to the observation of interest. Here, we use observations other than those exactly at $y_{i}$ because we believe they provide information about conditions at $y_{i}$. For example, if the tax system yields wildly different burdens for individuals with incomes slightly different from $y_{i}$, we believe that this tells us something about horizontal equity at $y_{i}$, where there may be very few observations with exactly that level of income. On the other hand, as the distance from $y_{i}$ grows, the similarity of individuals to those at $y_{i}$ falls. The "correct" kernel width should depend on how much noise we believe there is in $y_{i}$ as an indicator of "true" income class.

For compactness of notation, we express $f_{i}(\cdot)$ below as a function of the index gap, $k-i$, rather than the income difference $y_{k}-y_{i}$. We also suppress the limits of summation, which are the same as those in expression (4). We can rewrite (4) as:

(5) $w^{1-\rho}=\sum_{i}\left(\sum_{k} f_{i}(k-i) N_{k}\right) \tilde{y}_{i}{ }^{1-\rho}\left(1-\tilde{t}_{i}\right){ }^{1-\rho}\left(\frac{1}{\sum_{k} f_{i}(k-i) N_{k}} \cdot \sum_{k} f_{i}(k-i) \sum_{j}\left[\frac{y_{k}\left(1-t_{k j}\right)}{\tilde{y}_{i}\left(1-\tilde{t}_{i}\right)}\right]^{1-\gamma}\right)^{\frac{1-\rho}{1-\gamma}}$ where $\tilde{y}_{i}$ and $\tilde{t}_{i}$ are (as yet undefined) "representative" values for class $i$ and $t_{k j}=T_{k j} / y_{k}$ is the average tax rate for the $j^{\text {th }}$ member of group $i$. We wish to define $\tilde{y}_{i}$ and $\tilde{t}_{i}$ in a way that makes the last term measure horizontal equity. Rewrite (5) as: 


$$
w=\left[\sum_{i}\left(\sum_{k} f_{i}(k-i) N_{k}\right) \tilde{y}_{i}^{1-\rho}\left(1-\tilde{t}_{i}\right)^{1-\rho} H_{i}^{1-\rho}\right]^{\frac{1}{1-\rho}}
$$

where

$$
H_{i}^{1-\gamma}=\frac{1}{\sum_{k} f_{i}(k-i) N_{k}} \cdot \sum_{k} f_{i}(k-i) \sum_{j}\left[\frac{y_{k}\left(1-t_{k j}\right)}{\tilde{y}_{i}\left(1-\tilde{t}_{i}\right)}\right]^{1-\gamma}
$$

Let us impose the following requirements:

$$
\text { if } t_{k j} \equiv t \forall_{k, j} \text {, then } \tilde{t}_{i}=t
$$

(ii) if $t_{k j} \equiv t \forall_{k, j}$, then the term in (7) equals 1.

Condition (i) is very weak, requiring only that the representative tax rate for group $i, \tilde{t}_{i}$, must equal $t$ if everyone in the reference group has that tax rate. Condition (ii) is a normalization that will allow us to interpret the term in (7) as an index. Together, these assumptions imply that

$$
\frac{1}{\sum_{k} f_{i}(k-i) N_{k}} \cdot \sum_{k} f_{i}(k-i) N_{k} \frac{y_{k}{ }^{1-\gamma}}{\tilde{y}_{i}^{1-\gamma}}=1
$$

or, rearranging terms,

$$
\tilde{y}_{i}^{1-\gamma}=\sum_{k} a_{k i} y_{k}{ }^{1-\gamma} \quad \text { or } \quad \tilde{y}_{i}=\left(\sum_{k} a_{k i} y_{k}{ }^{1-\gamma}\right)^{\frac{1}{1-\gamma}}
$$

where

$$
a_{k i}=\frac{f_{i}(k-i) N_{k}}{\sum_{k} f_{i}(k-i) N_{k}} ; \quad \sum_{k} a_{k i}=1
$$

That is, $\tilde{y}_{i}{ }^{1-\gamma}$ is a weighted average of nearby values of $y_{k}{ }^{1-\gamma}$, with weights based on population density $N_{k}$ and the function $f_{i}(\cdot)$. 
Let us pause a moment to interpret expression (9). In the special case where $f_{i}(\cdot)$ is a spiked distribution at income level $y_{i}$ - corresponding to the approach for which only those at precisely the same income level belong to $i$ 's reference group - expression (9) implies that $\tilde{y}_{i}=y_{i}$. For general specifications of $f_{i}(\cdot)$ but with $\gamma=0, \tilde{y}_{i}$ is a simple arithmetic average of the income in $i$ 's reference group. However, for $\gamma>0, \tilde{y}_{i}$ will give more weight to those in the reference group with incomes below $y_{i}$ than to those with incomes above $y_{i}$, reflecting the prefences of the social welfare function that weight those with lower income more heavily.

Using (9) and (10), we may rewrite (7) as:

$$
H_{i}^{1-\gamma}=\frac{\sum_{k} f_{i}(k-i) N_{k} y_{k}{ }^{1-\gamma} \cdot \frac{1}{N_{k}} \sum_{j}\left(1-t_{k j}\right)^{1-\gamma}}{\sum_{k} f_{i}(k-i) N_{k} y_{k}{ }^{1-\gamma} \cdot\left(1-\tilde{t}_{i}\right)^{1-\gamma}}=\frac{\sum_{k} b_{k i} \cdot \frac{1}{N_{k}} \sum_{j}\left(1-t_{k j}\right)^{1-\gamma}}{\left(1-\tilde{t}_{i}\right)^{1-\gamma}}
$$

where

$$
b_{k i}=\frac{f_{i}(k-i) N_{k} y_{k}{ }^{1-\gamma}}{\sum_{k} f_{i}(k-i) N_{k} y_{k}{ }^{1-\gamma}} ; \quad \sum_{k} b_{k i}=1
$$

Expression (11) encompasses the component of social welfare that depends on variations among individuals in the reference group for income class $i$. Thus far, we have normalized this measure so that $H_{i}=1$ when all tax rates are equal. As yet, we have not defined the representative tax rate for this group, $\tilde{t}_{i}$, except to impose the obvious condition that it equal $t$ if all individuals in the reference group face a tax rate equal to $t$. But there are many ways to define an average over this group when their tax rates vary. It turns out, though, that only one approach provides an intuitive 
interpretation of $H_{i}$ as a measure of horizontal equity. To see this, we impose another condition on expression (7):

(iii) As defined in (7) and (11), $H_{i}$ achieves its maximum when all reference group tax rates are equal.

With this additional condition, we are now in a position to prove the following result:

Proposition: Conditions (i)-(iii) are satisfied if and only if $\tilde{t}_{i}$ is defined by the following weighted average of the average tax rates for each income class $k$ in $i$ 's reference group:

$$
\tilde{t}_{i}=\sum_{k} b_{k i}\left(\frac{1}{N_{k}} \sum_{j} t_{k j}\right)
$$

Before proceeding to the proof, consider this definition, which parallels that of $\tilde{y}_{i}$ in (9). For the special case in which $f_{i}(\cdot)$ is a spiked distribution at $i, \tilde{t}_{i}$ is the simple average tax rate at income $i$. For general specifications of $f_{i}(\cdot)$ but with $\gamma=0, \tilde{t}_{i}$ is an average tax rate for $i$ 's reference group, weighted by income (see (12)). However, for $\gamma>0, \tilde{t}_{i}$, like $\tilde{y}_{i}$, will give more weight to the income of those in the reference group with lower incomes.

proof: We first prove sufficiency, that the three conditions are satisfied if $\tilde{t}_{i}$ is defined by expression (13). Clearly, this definition of $\tilde{t}_{i}$ satisfies conditions (i) and (ii). To show that (iii) also holds, consider a variation, $\varepsilon$, in two tax rates, say $t_{k j}$ and $t_{l m}$, that keeps $\tilde{t}_{i}$, as defined in (13), constant. This implies that:

$$
b_{k i} \cdot \frac{1}{N_{k}} \frac{d t_{k j}}{d \varepsilon}+b_{l i} \cdot \frac{1}{N_{l}} \frac{d t_{l m}}{d \varepsilon}=0
$$


The derivative of $H_{i}^{1-\gamma}$ with respect to this same variation is proportional to ${ }^{5}$ :

$$
-(1-\gamma) b_{k i} \cdot \frac{1}{N_{k}}\left(1-t_{k j}\right)^{-\gamma} \frac{d t_{k j}}{d \varepsilon}-(1-\gamma) b_{l i} \cdot \frac{1}{N_{l}}\left(1-t_{l m}\right)^{-\gamma} \frac{d t_{l m}}{d \varepsilon}
$$

Substituting (15) into (14) yields:

$$
-(1-\gamma) b_{k i} \cdot \frac{1}{N_{k}} \frac{d t_{k j}}{d \varepsilon}\left[\left(1-t_{k j}\right)^{-\gamma}-\left(1-t_{l m}\right)^{-\gamma}\right]
$$

which vanishes when $t_{k j}=t_{l m}$. This will hold for all variations in tax rates if and only if $t_{k j} \equiv t$ $\forall_{k, j}$, for some value $t$. Although this result concerns $d H_{i}^{1-\gamma} / d \varepsilon$, it also holds for

$$
\frac{d H_{i}}{d \varepsilon}=\frac{1}{1-\gamma}\left(H^{1-\gamma}\right)^{\frac{1}{1-\gamma}-1} \frac{d H_{i}^{1-\gamma}}{d \varepsilon}
$$

which will not vanish unless $d H_{i}^{1-\gamma} / d \varepsilon$ does.

When $t_{k j}=t_{l m}$, the second-order condition for $H_{i}^{1-\gamma}$ with respect to $\varepsilon$ based on (16) (again using (14) to substitute into the expression) is:

$$
-\gamma(1-\gamma)\left(\frac{b_{k i}}{N_{k}} \frac{d t_{k j}}{d \varepsilon}\right)^{2}\left[\frac{\left(1-t_{k j}\right)^{-(\gamma+1)}}{b_{k i} / N_{k}}+\frac{\left(1-t_{l m}\right)^{-(\gamma+1)}}{b_{l i} / N_{l}}\right],
$$

which has the same sign as $-(1-\gamma)$. Given the relationship between $H_{i}^{1-\gamma}$ and $H_{i}$, this implies that the second-order conditions for a maximum for $H_{i}$ are satisfied when all tax rates are equal.

\footnotetext{
${ }^{5}$ The denominator in (11) is fixed by assumption; the term in (15) is the change in the numerator in (11).
} 
To prove necessity, that only the definition of $\tilde{t}_{i}$ in (13) satisfies conditions (i)-(iii), suppose there were some other definition that also worked. We could again consider a variation $\varepsilon$ holding $\tilde{t}_{i}$ constant, leading to expression (15). We would again require that the term in (15) vanish if and only if $t_{k j}=t_{l m}$. This, in turn, would imply that expression (14) must hold, which implies that $\tilde{t}_{i}$ must be of the form $g(z)$, where $z$ is the term on the right-hand side of (13). However, only the function $g(z)=z$ also satisfies condition (i).

To recapitulate, if we define average income $\tilde{y}_{i}$ using (9) and the average tax rate $\tilde{t}_{i}$ using (13), then the last component of the social welfare function defined in (6),

$$
H_{i}=\left[\sum_{k} b_{k i} \cdot \frac{1}{N_{k}} \sum_{j}\left(\frac{1-t_{k j}}{1-\tilde{t}_{i}}\right)^{1-\gamma}\right]^{\frac{1}{1-\gamma}}
$$

is an index of horizontal equity, satisfying the intuitive requirement that it achieves its maximum (normalized to 1) when the average tax rates of all those in the reference group are equal. Note that this index depends on the "local" inequality aversion parameter $\gamma$, but not on the "global" inequality parameter $\rho$. The weights assigned to different individuals in the reference group, $b_{k i}$ as defined in (12), do depend on the value of $\gamma$, and assign more weight to those in the reference group with lower income.

We can use (6) to decompose changes in social welfare over time into those due to changes in the level and distribution of income, changes in the burden and the progressivity of the tax system, and changes in the degree of horizontal equity, by holding the terms $\tilde{y}_{i},\left(1-\tilde{t}_{i}\right)$, and $\widetilde{H}_{i}$, respectively, constant. This decomposition holds even in the event that $\gamma=\rho$, although 
the motivation for the exercise, notably the specification of a reference group through the definition of $f(\cdot)$, clearly hinges on the fact that this equality need not hold.

An issue that has often arisen in the literature is how we should weight local measures of horizontal equity into a single, overall index. For measures that start with some assumed metric for measuring deviations, there may be no obvious answer. Here, though, because our metric is defined by an underlying welfare function, the answer is dictated by decomposition procedure

just followed. We may define an aggregate index of horizontal equity as that constant value, $\tilde{H}$, for which the social welfare function takes on the same value as it does for the given values of $H_{i}:$

$$
\tilde{H}=\left[\frac{\sum_{i}\left(\sum_{k} f_{i}(k-i) N_{k}\right) \tilde{y}_{i}^{1-\rho}\left(1-\tilde{t}_{i}\right)^{1-\rho} H_{i}^{1-\rho}}{\sum_{i}\left(\sum_{k} f_{i}(k-i) N_{k}\right) \tilde{y}_{i}^{1-\rho}\left(1-\tilde{t}_{i}\right)^{1-\rho}}\right]^{\frac{1}{1-\rho}}
$$

This overall index does depend on $\rho$. Intuitively, we will care more about horizontal equity at lower income levels, the larger is the value of $\rho$, because we care more, in general, about what happens to lower-income individuals.

\section{Discussion}

Before presenting empirical applications of the measure just derived, it will be useful to review some of its attributes, in light of the difficulties mentioned above in the introduction.

First of all, the measure is derived from a well-behaved social welfare function, so it will not lead to any anomalies inherent in alternative approaches that do not, for example, respect the Pareto principle in a world of certainty. While we claim no particular knowledge of the function's specific parameter values, the approach provides a framework with logical 
foundations that can serve as a useful tool for evaluating alternative policy options. It allows those performing the evaluation to specify their own preferred parameter values within a single framework, rather than having the values be implicit in the choice of one measure over another.

As discussed above, the particular functional form used here does allow the well-being of reference group members to be relevant to comparisons of alternative outcomes, even if these members themselves are indifferent between such outcomes. Also, because the function is concave in the assumed linear individual utilities, its use in evaluating uncertain outcomes would not satisfy the Pareto criterion as characterized in terms of individual, ex ante, expected utilities. ${ }^{6}$ We view neither of these attributes as particularly problematic. As discussed above, the whole notion of horizontal equity suggests the relevance of reference groups; that such groups should matter should hardly be seen as an anomaly. The extension of the Pareto principle to apply to $e x$ ante expected utilities requires not only that individual preferences satisfy the von NeumannMorgenstern axioms, but also that social welfare cannot be averse to ex post inequalities in the distribution of income, a requirement that strikes us as unnecessarily restrictive. How to think about equity in general and horizontal equity in particular becomes more complicated in the presence of uncertainty, and is not a subject pursued further here.

Second, the measure is scaled in the same units as other factors that determine social welfare, so we can make meaningful comparisons between a change in horizontal equity and, say, an increase in overall taxes or a decrease in the dispersion of income. Third, because the measure of horizontal equity is derived through a decomposition of the social welfare function (see (6)), there is no problem in potential "double-counting" of variations that affect both horizontal and vertical equity. A change in any individual's tax burden will affect the social

\footnotetext{
${ }^{6}$ For example, since utility is linear in income, individuals would be willing to take on any risk in exchange for an arbitrarily small compensation, whereas society would not if it maximizes expected social welfare.
} 
welfare function through many channels, some through different indices $H_{i}$ and some through average tax rates $\tilde{t}_{i}$, but these effects will each be distinctly measured. Finally, the measure allows great flexibility in the definition of "equals," so that small variations in income need not trigger discontinuous changes in reference group membership.

This new measure also suggests a response to a problem raised in the literature by Stiglitz (1982), who observed that, in a more complicated model of the economy, the "utility possibilities frontier" facing the social welfare planner might not be convex. ${ }^{7}$ In such a situation, as depicted by Atkinson (1980) and repeated in Figure 1, the government might improve social welfare by providing two otherwise identical individuals with different tax burdens and utility levels, as depicted at points A and B. Based on this result, one can argue that horizontal equity need not be subsumed by general social welfare maximization, and that, if horizontal equity is desirable in its own right, it might be appropriately included as a separate argument of the social welfare function. In a sense, this is precisely what our approach does. By allowing social welfare to be more averse to horizontal inequity than to vertical inequity, it can permit outcomes that push "equals" closer together. Indeed, for sufficiently HE-averse preferences - the extreme being the Leontief preferences depicted by the dashed social indifference curve in Figure 1 - no horizontal inequity would result, for then point $\mathrm{C}$ would be most preferred. However, our approach has the advantage that this outcome is generated in the context of social welfare maximization, and does not require the inclusion of an $a d$ hoc, distinct measure of horizontal equity subject to the various problems touched on above.

Figures 2 and 3 illustrate the ability of our social welfare function to accommodate sharply different preferences toward horizontal and vertical inequality. They illustrate a simple

\footnotetext{
${ }^{7}$ With income and taxes exogenous in our model, the frontier is linear.
} 
economy with three individuals. Mr. 1 is poor, having roughly half the income of Mr. 2 and Mr. 3 , who are a single comparison class for the purposes of horizontal equity. The origin, which is the set of incomes $\{0.2,2,2\}$, is in the back left hand corner. In the first example, Figure $2, \rho=$ $\gamma=2$, so the aversion to horizontal inequality is not particularly strong. ${ }^{8}$ Since Mr. 1 is poorer than the others, we need to give Mr. 2 and Mr. 3 much more income than we take away from Mr. 1 in order to maintain indifference. But the indifference surface is relatively flat in the Mr.2-Mr. 3 plane: inequality between Mr. 2 and Mr. 3 is not heavily penalized. Figure 3 increases the parameter $\gamma$ to 50, making preferences toward horizontal inequality between Mr. 2 and Mr. 3 almost Leontief. As income is taken away from Mr. 1, the total income that must be devoted to Mr. 2 and Mr. 3 to maintain indifference is much lower when they receive the same income.

\section{Initial Applications}

To illustrate our measure of horizontal equity, we use two data sets. Each is a public-use sample of individual income tax returns. The first, the Michigan tax panel, has the advantage of following the same group of taxpayers over time, but also has two disadvantages. It has a relatively small number of households (about 5,000) and a terminal year of 1990, before many of the recent changes in the income tax code took place. Our second data set, the annual NBER tax file, does not provide the advantages of a panel, but has several other advantages. First, it is currently available for 1994 - after the 1993 tax increase. Moreover, it has roughly 96,000 households, with the added benefit of significant oversampling of high-income households. Finally, in conjunction with the NBER TAXSIM model, this data set can be used to simulate the effects of a tax law change on household tax liabilities.

\footnotetext{
${ }^{8}$ For simplicity, we are assuming here that the function $f(\cdot)$ is a spike, so that Mr. 1 is not in the reference group for Mr. 2 and Mr. 3, and vice-versa.
} 
We examine first the results from the Michigan panel. For this data set, we define each household to be its own income class. That is, we set $N_{i}=1 \forall i$. Initially, we consider each household without regard to its filing status or the number of individuals in the household. That is, for each household, we consider only adjusted gross income (AGI) and federal income tax.

Figure 4 presents graphs of $H_{i}$ for the panel, with both income and tax liability averaged over the panel's 12-year period. Our sample of 5022 consists of all observations with complete income and tax data for the full period, less 216 households that appeared to have anomalous tax or income patterns, based on very gross filters. ${ }^{9}$ For this and most other figures that follow, we plot $H_{i}$ against household income percentile. To calculate a household's percentile in the income distribution, we first order households in ascending order of average income, giving each household its 12-year average sample weight, and then dividing by the sum of average sample weights. Thus, the household with income greater than other households with 35 percent of the sample weight will be located at the $35^{\text {th }}$ percentile of the income distribution. Because the values of $H_{i}$ trend downward at the very top of the distribution, we truncate the graphs at the $98^{\text {th }}$ percentile in order to make more subtle variations at other incomes distinguishable.

The figure presents nine different graphs of $H_{i}$, based on all possible combinations of three different assumptions about the "local" inequality aversion parameter, $\gamma$, and three different shapes of the function $f_{i}(\cdot)$. For $\gamma$, we consider values of $.5,2$, and 5 , meant to reflect very wide variation in preferences, from mild to strong aversion to inequality. For $f_{i}(\cdot)$, we use the normal distribution, letting this distribution vary with respect to the degree of reference group dispersion - the distribution's standard deviation - and the extent to which this dispersion changes with

\footnotetext{
${ }^{9}$ Most of the households eliminated had negative AGI or a tax rate greater than 100 percent in at least one panel year. A small additional number were eliminated because of a tax rate that deviated by more than 25 percentage points from the household's 12-year average in any year. We omitted one additional household with a huge deviation in income to near 0 in one year.
} 
income. ${ }^{10}$ We consider three patterns. One specification sets the standard deviation equal to $.10 y_{i}$. The second specification, which we refer to as "log" scaling, sets the standard deviation equal to $x \ln \left(y_{i}\right)$, with $x$ scaled so that the distribution is the same at median income, $y^{m}$, i.e., $x=$ $.10 y^{m} / \ln \left(y^{m}\right)$. These two specifications of $f_{i}(\cdot)$ differ in the extent two which the relevant “distance" for membership in an income level's reference group grows with income. The first approach assumes that the distance grows in proportion to income, so that an individual with an income of $\$ 100,000$ would be as relevant for reference when $y_{i}=\$ 200,000$ as an individual with an income of $\$ 10,000$ would be for $y_{i}=\$ 20,000$. The log scaling approach slows this widening of the income dispersion of the reference group, implying that the relative weight given to someone with $\$ 10,000$ of income in the second case would correspond to the weight given to someone with $\$ 182,000$ of income in the first case, rather than $\$ 100,000$. Our third specification for $f_{i}(\cdot)$ also uses log scaling, but with a larger value of $x, .25$ rather than .10 .

Figure 4 provides a number of interesting results. First, our measure of horizontal equity generally falls with $\gamma$ - the greater the aversion to local inequality, the lower the index of horizontal equity. This is hardly surprising - we would expect to be willing to "pay more" to avoid dispersion, the higher our aversion to it. We can scale the values of $H_{i}$ in terms of an equivalent increase in the average tax rate, $\tilde{t}_{i}$. From (6), the increase in the tax rate, say $\Delta_{i}$, that has the same impact on social welfare as the deviation of $H_{i}$ from 1 , is:

$$
\Delta_{i}=\left(1-H_{i}\right)\left(1-\tilde{t}_{i}\right)
$$

Thus, for values of $H_{i}$ near .9950-.9975, the range for $\gamma=5$, and $\tilde{t}_{i}$ around $.15, \Delta_{i}$ equals roughly .002 to .004 , or .2 to .4 percentage points. That is, the existing horizontal equity, as measured,

\footnotetext{
${ }^{10}$ Because the income distribution is bounded, the distributions actually used are truncated normals.
} 
costs society as much as an across-the-board increase of .2 to .4 percentage points in the average income tax rate.

One might be interested in how $H_{i}$ varies with income rather than location in the income distribution. Figure 5 repeats one of the nine graphs of $H_{i}$ from Figure 4, for $\gamma=2$ and $\log$ scaling of .10, against two alternative series on the horizontal axis: income percentile (bottom axis), as in Figure 4, and real (1990\$) income (top axis). Because of the skewness of the income distribution, the second curve is compressed to the left, relative to the first.

A central question that always arises in attempting to define horizontal equity - and one which our new approach must confront as well - is which adjustments are "correct" - moving the tax burden closer to equitable - and which adjustments represent deviations from an equitable outcome. One could always do away with any measured horizontal inequity simply by assuming that any differences in burden between apparent equals are due to the fact that they really do differ in some respect that is being recognized by the tax system.

For example, if a certain expense, say for medical care, should not be counted as income, then allowing a deduction for it should improve our measure of horizontal equity, if we also measure income by subtracting this expense. On the other hand, if we ignore such "appropriate" adjustments to income in our computation, then we may see a deviation in an average tax rate where none really exists. Thus, the accuracy of our measure of horizontal equity depends on whether we have made the right adjustments to income. We do not wish to pursue this issue fully here, but one important potential adjustment that relates to our consideration of the marriage penalty relates to household size, in particular the number of adults in a household.

Presumably, the view that such an adjustment is needed underlies the fact that married couples who file jointly receive a larger standard deduction and wider tax brackets than single 
filers. Indeed, the notion of a "marriage tax" seems predicated on the view that the tax system doesn't adjust enough for joint filers. But this leaves the question of how much we should adjust the income level of a joint-filing household in order to compare it to that of a single filer. Figure 6 considers three alternatives. ${ }^{11}$ For the reference group function, $f_{i}(\cdot)$, based on the $.10 \log$ scaling assumption, and all three values of $\gamma$ from Figure 1, we measure each household's income (and taxes) at its original value, its original value divided by $\sqrt{2}$, and its original value divided by 2 . That is, we consider equivalence scales of $1, \sqrt{2}$, and 2 , in deciding how to describe the taxes and income per "unit" in the household. The logic of not dividing by 2 is that there are economies of scale in living arrangements, so that the living standard for joint filers may be higher than that of single filers with half their combined income. ${ }^{12}$

A striking pattern in the figure is that as the adjustments by $\sqrt{2}$ and then 2 are made in succession, the $H_{i}$ curves rise almost uniformly. This result suggests that horizontal inequity may not be as bad as the unadjusted curves suggest. But it also has another interpretation, if we think that the full adjustment by 2 represents an excessive correction: that one of the sources of horizontal inequity may be the overcorrection of tax brackets for joint filers. We return to this issue below, when considering the impact of potential reforms.

Figure 7 presents $H_{i}$ curves for each individual year in the Michigan tax panel, using the full sample of 5,022, for $.10 \log$ scaling and $\gamma=2$. The evolution of the curves is quite interesting, in light of the fact that the two most important tax changes occurred in 1981, with the passage of the Economic Recovery Tax Act, and in 1986, with the Tax Reform Act of 1986. The

\footnotetext{
${ }^{11}$ For this figure, we eliminated all observations that experienced a change in filing status during the 12-year period, moving us from a sample of 5,022 to one of 3,389 .

${ }^{12}$ Below, when discussing the marriage penalty, we consider additional adjustments for family size. Determining the adjustment most appropriate for evaluating tax payments is a subject worthy of further discussion, but beyond the scope of our current analysis.
} 
most striking pattern in the figure is the general shift upward over time, at least since 1981, which is for most of the income distribution the lowest curve in the figure. Indeed, for most income levels above the $25^{\text {th }}$ percentile, the curves for years $1987-1990$ - the only four years in the sample after the individual income tax provisions of the 1986 act took effect - are the four highest in the figure. Only at lower income levels is the pattern different. There, the years 1979 and 1980 rate highest. From this simple analysis, one might tentatively conclude that the 1981 act worsened horizontal equity at most income levels, particularly at the low end, and that the 1986 act reversed the pattern, particularly at middle and upper income levels.

\section{The Marriage Penalty}

In Figure 8, we turn to our second data set, the NBER 1994 sample. Because of the size of this data set $-90,132^{13}$ - it was computationally infeasible to define each individual observation as an income group. Instead, we defined each group $i$ to include 20 individuals, producing a similar number of groups $-4,506$ - as in the previous exercise. ${ }^{14}$ Figure 8 repeats the graphs of $H_{i}$, for $.10 \log$ scaling, $\gamma=.5$ and 2 , and joint filer adjustments of $1, \sqrt{2}$, and 2 . The general patterns are similar to those observed earlier, particularly that for 1990 in Figure 7, with a general downward drift in $H_{i}$ as income rises, followed by a slight rise around the $70^{\text {th }}$ percentile, and then a resumption of the downward trend, accelerating near the top. One interesting difference is that the impact of the size adjustment to income for joint filers appears to raise $H_{i}$ less than was the case for the 1979-90 average. Taking a "reverse engineering" approach and asking what "correct" joint filer size adjustment would be "implied by" the 1994

\footnotetext{
${ }^{13}$ This number is net of the elimination of 6,252 records with negative AGI or a tax rate over 100 percent.

${ }^{14}$ For simplicity, to make the number of observations divisible by 20 , we randomly dropped 12 observations.
} 
tax system if that system's tax adjustments were designed to minimize horizontal equity, would imply a smaller such adjustment than would the earlier tax system.

How would these results differ if we attempted to "solve" the marriage penalty? As is well known, finding such a solution presents a problem much thornier than is sometimes suggested in political debates. Even comparing joint filers to two single filers in identical circumstances, the effect of marriage is often to reduce taxes rather than to raise them, leading not to a marriage penalty but a marriage "bonus." (CBO 1997). Even more problematic is the question of how to compare joint filers with individual single filers in different situations - the question posed above when considering the "appropriate" joint filer adjustment for measuring a family's income level. Still, many alternative "solutions" to the marriage penalty have been proposed, generally structured to reduce the taxes of joint filers. We consider the impact of one such scheme, which would divide all income of joint filers equally between spouses, along with deductions and exemptions not directly tied to either taxpayer, and then allowing each spouse to file as a single taxpayer. This scheme is roughly equivalent to providing joint filers with tax brackets that are twice as large as those facing single filers. Clearly, such a scheme would reduce the taxes of nearly all joint filers, because the current brackets are based on a lower ratio. ${ }^{15}$ But whether this improves horizontal equity or not depends on whether joint filers now face burdens higher than those of single filers to whom they are being compared. The relevant comparison groups, in turn, depend on how we adjust for family size when computing income.

\footnotetext{
${ }^{15}$ The zero-bracket amount for a joint-filing couple, equal to the standard deduction plus two exemptions, is $\$ 11,650$ for 1998 , or roughly $12 / 3$ times the single filer's zero-bracket amount of $\$ 6,950$. The next two bracket floors, for the $28 \%$ and $31 \%$ rates, roughly preserve this ratio, at $\$ 42,350$ and $\$ 102,300$ for joint filers and $\$ 25,350$ and $\$ 61,400$ for single filers. However, the floors for the last two brackets $(36 \%$ and $39.6 \%)$ for joint filers are 1.2 and 1.0 times those of single filers.
} 
Figures 9-11 illustrate the effect of this change on our measure of horizontal equity. Each figure repeats two of the six graphs from Figure 8 , for $\gamma=.5$ and 2 and one of the three joint filer size adjustments, and also presents two comparable graphs for the alternative tax system aimed at "solving" the marriage penalty. Figure 9 makes no joint filer adjustment, Figure 10 divides the income of joint filers by $\sqrt{2}$, and Figure 11 divides income of joint filers by 2 .

Not surprisingly, the results in Figure 9 suggest that horizontal equity falls. If no family size adjustment were appropriate, then the current tax system already would be too generous to joint filers, and this system would exacerbate this bias. The pattern of this impact, occurring primarily in the upper-middle income range, may be attributable in part to the fact that the current tax system becomes less favorable to joint filers as incomes rise (see footnote 15). Thus, if we view size adjustments as inappropriate, we are closer to the correct treatment under current law and deviate more from this treatment under the proposal. However, this intuition fails to explain why there is no apparent worsening of horizontal equity at lower income levels.

Figure 10 illustrates the impact of reform if the appropriate income adjustment is to divide joint income by $\sqrt{2}$. The pattern is similar to that in Figure 9. As expected, the decline in measured horizontal equity is smaller in general, because the appropriate treatment is now assumed to involve some family size adjustment. Again, though, the pattern observed for incomes below the median, in this case showing a small improvement in horizontal equity, is difficult to reconcile with the fact that the tax system is moving farther away from the size adjustment assumed to be appropriate.

The adjustments in Figure 11 are based on an equivalence scale of 2, essentially consistent with the policy being undertaken. If the only systematic variation in tax burdens between single filers and joint filers under current law were attributable to differences in tax 
schedules, the new tax policy would eliminate all horizontal equity attributable to differences in filing status. Yet measured horizontal equity does not rise uniformly in the figure. Rather, it rises at lower income levels, as before, and now also at higher income levels, but still falls at middle income levels. This confirms what the other figures suggest, that the relative treatment of joint filers and single filers under the current code differs in ways not captured by the tax schedule itself, with these differences varying over the income distribution.

One systematic difference clearly omitted thus far is the presence of dependents, for whom the tax code provides additional exemptions. This likely reduces the relative tax burdens of joint filers, and might help explain why the reform appears to worsen horizontal equity at some income levels, even in Figure 11. But ignoring dependents also means that we are probably adjusting family size incorrectly, and therefore understating the extent to which joint filers, who are more likely to have dependents, are unfavorably treated under current law.

Figures 12 and 13 illustrate the impact of the tax reform, now adjusting family income by $\sqrt{N}$ and $N$, respectively, where $N$ is the total number of individuals in the family's household. As one might expect, the latter figure now shows that the proposed reform raises horizontal equity at all income levels, for it is based on a size adjustment that implies that the current tax system treats joint filers with dependents far too severely. But adjusting by $\sqrt{N}$ still leaves a large share of the income distribution over which the index falls. This suggests that joint filers may be taking greater advantage of other provisions in the tax code that reduce tax payments (for example, mortgage interest deductions), making their current treatment more favorable than is implied by the simple rate schedules themselves.

Together, these figures confirm that the extent to which the marriage penalty should be "corrected" depends on how great it is measured to be at present. But they also suggest that, 
whatever the proper adjustment for the income of joint filers, the penalty may be least in need of correction at upper middle income levels.

\section{Conclusions}

We have derived a measure of horizontal equity that allows for separate social preferences toward vertical and horizontal equity. As an illustration of the application of our measure, we have explored the change in horizontal inequality of the U.S. federal income tax, and examined a recent proposal to undo the "marriage penalty".

Conditional on known values of preferences toward vertical and horizontal inequality, our work is a contribution to the positive theory of measurement. While we are unaware of any fundamental normative justification for the constraint - which has so often been imposed in the past - that society's preferences toward the two types of inequality by identical, there is also little guidance as to the appropriate relative weighting, or how to determine individual reference groups. The exploration of the consequences of different attitudes toward horizontal and vertical inequality is an important subject of future inquiry. 


\section{References}

Aronson, J. Richard, Paul Johnson, and Peter J. Lambert, 1994, "Redistributive Effect and Unequal Income Tax Treatment,” Economic Journal 104, March, 262-70.

Atkinson, Anthony B., 1970, “On the Measurement of Inequality,” Journal of Economic Theory 2, 244-63.

Atkinson, Anthony B., 1980, "Horizontal Equity and the Distribution of the Tax Burden," in H. Aaron and M. Boskin, eds., The Economics of Taxation, Brookings Institution, Washington, 3-18.

Congressional Budget Office, 1997, For Better or for Worse: Marriage and the Federal Income Tax, June, 1-56.

Epstein, Larry G. and Stanley E. Zin, 1989, "Substitution, Risk Aversion, and the Temporal Behavior of Consumption and Asset Returns: A Theoretical Framework, Econometrica 57, July, 937-69.

Feldstein, Martin, 1976, "On the Theory of Tax Reform," Journal of Public Economics 6, July/August, 77-104.

Kaplow, Louis, 1989, "Horizontal Equity: Measures in Search of a Principle," National Tax Journal 42, 139-54.

Kreps, David, and Evan L. Porteus, 1978, "Temporal Resolution of Uncertainty and Dynamic Choice Theory," Econometrica 46, January, 185-200.

King, Mervyn, 1983, “An Index of Inequality: With Applications to Horizontal Equity and Social Mobility,” Econometrica 51, January, 99-115.

Lambert, Peter J. and Xavier Ramos, 1997, "Horizontal Inequity and Vertical Redistribution," International Tax and Public Finance 4, January, 25-37.

Musgrave, Richard A., 1959, The Theory of Public Finance, McGraw-Hill, New York.

Plotnick, Robert, 1981, “A Measure of Horizontal Inequity,” Review of Economics and Statistics 63, May, 283-88.

Roemer, John E., 1996, Theories of Distributive Justice, Harvard University Press, Cambridge.

Rosen, Harvey S., 1978, “An Approach to the Study of Income, Utility, and Horizontal Equity," Quarterly Journal of Economics 92, May, 307-22. 
Stiglitz, Joseph E., 1982, "Utilitarianism and Horizontal Equity: The Case of Random Taxation," Journal of Public Economics 18, 1-33.

Yatchew, Adonis, 1998, "Nonparametric Regression Techniques in Economics," Journal of Economic Literature 36, June, 669-721. 
Figure 1. Horizontal Equity and Nonconvexity

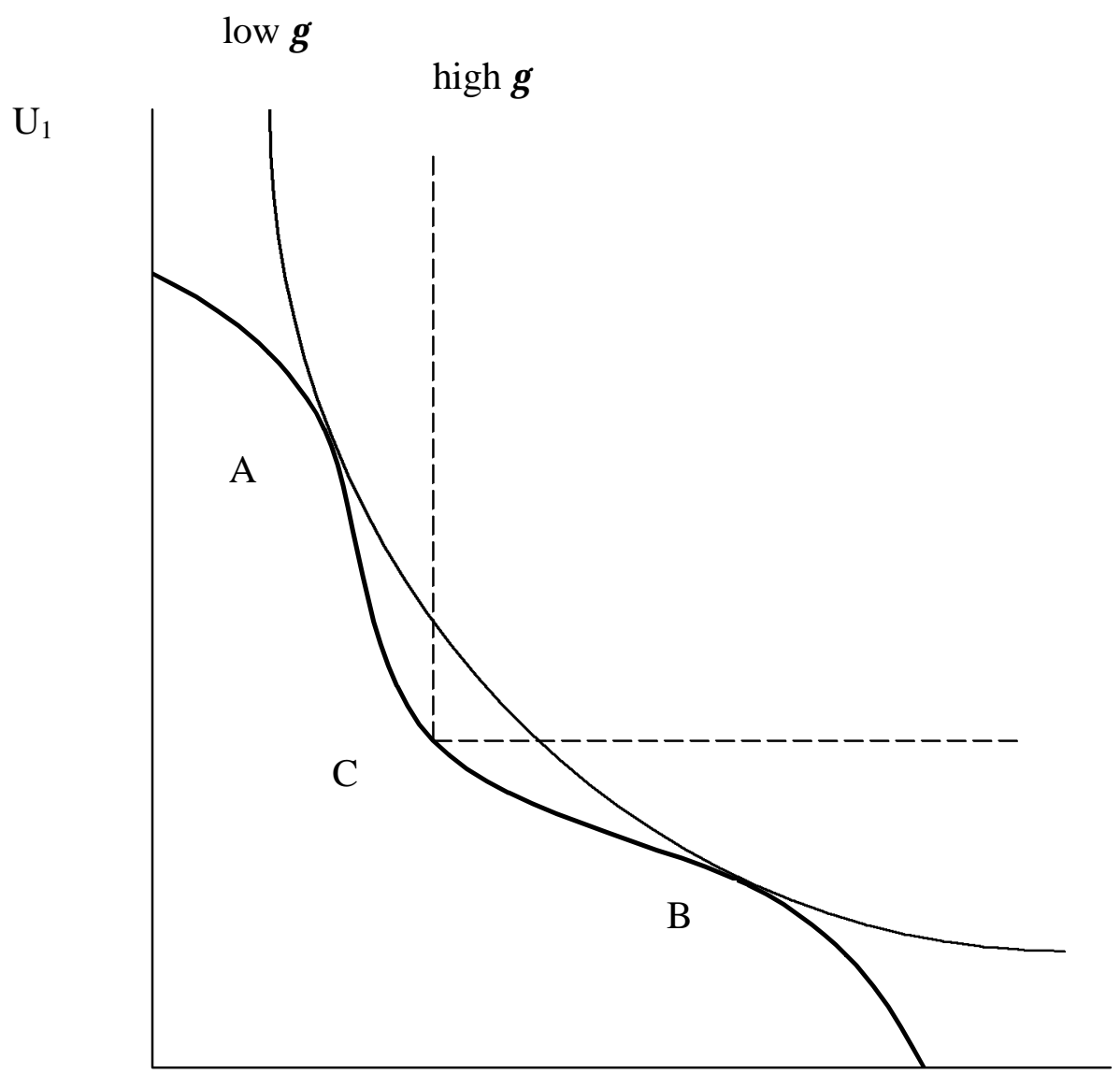

$\mathrm{U}_{2}$ 
Figure 2. Social Welfare Function Indifference Surface

$$
(\gamma=2, \rho=2)
$$

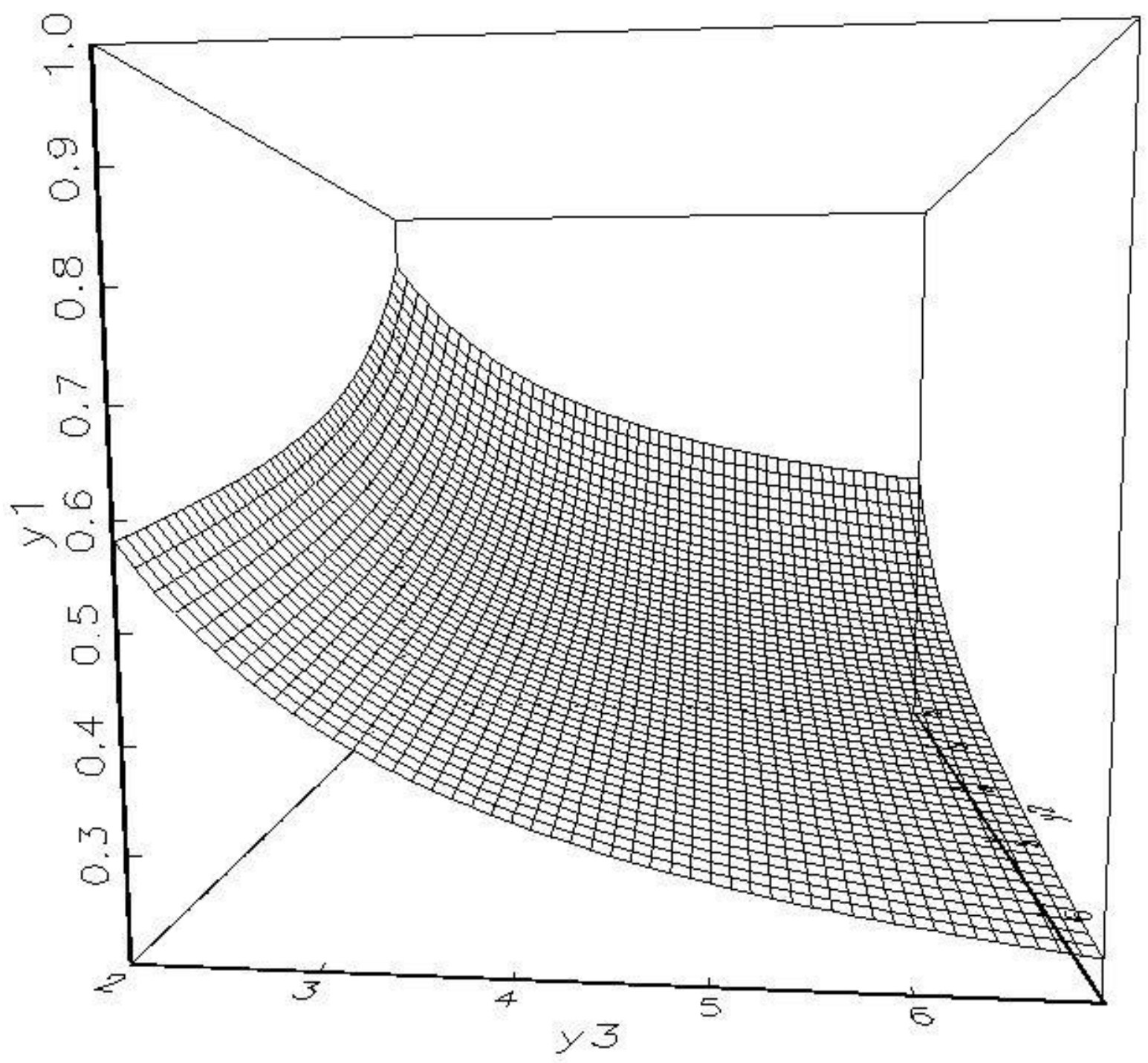


Figure 3. Social Welfare Function Indifference Surface

$$
(\gamma=50, \rho=2)
$$

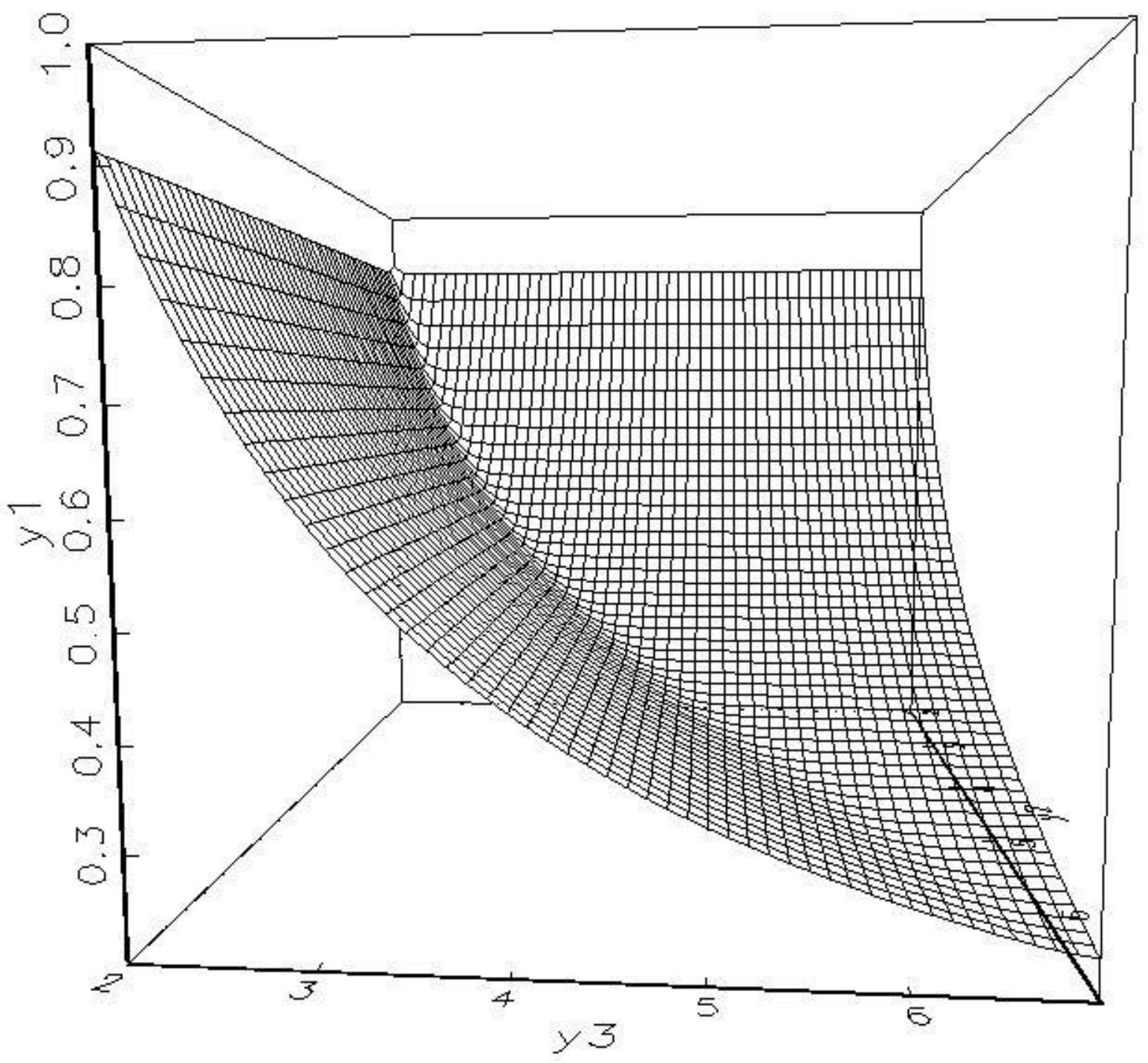


Figure 4. Index of Horizontal Equity: 12-Year Average, 1979-90

$$
(\gamma=.5,2,5 ; \text { Scaling }=.10, \log \text { Scaling }=.10, .25)
$$

Index

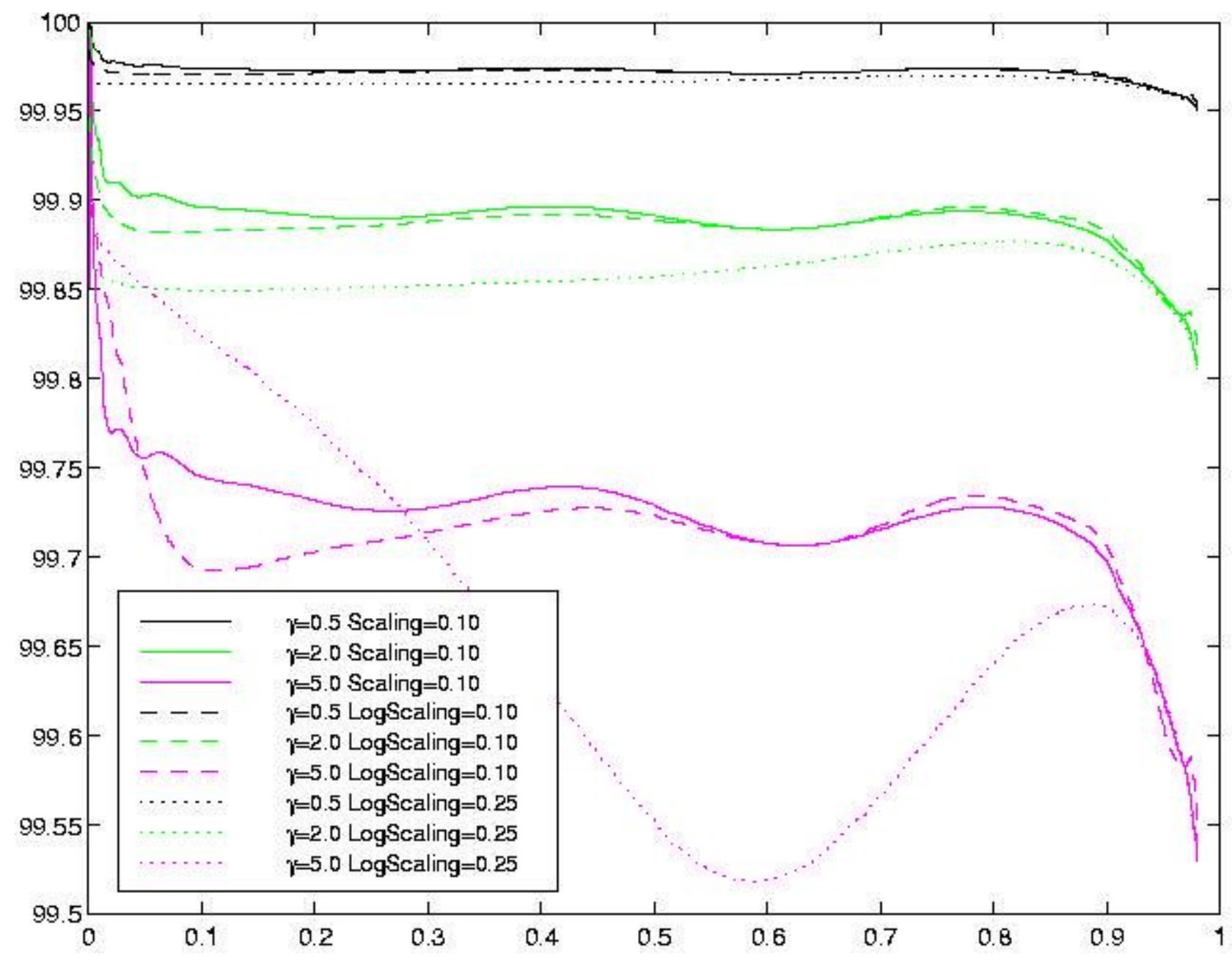

Income Percentile 
Figure 5. Index of Horizontal Equity: By Alternative Income Classes $(\gamma=2 ;$ Log Scaling $=.10)$

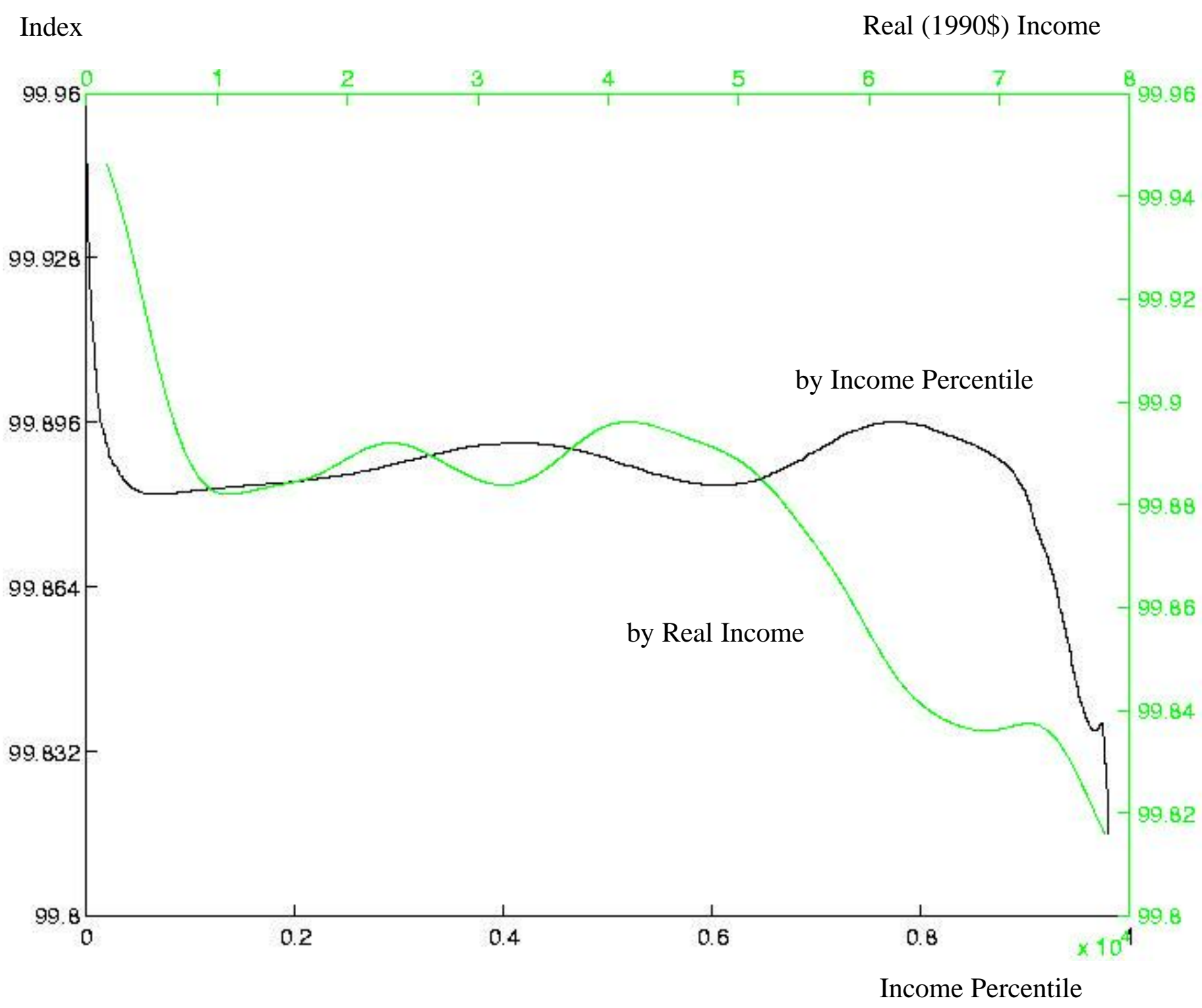


Figure 6. Index of Horizontal Equity: Alternative Equivalence Scales

$(\gamma=.5,2,5 ;$ Log Scaling $=.10)$

Index

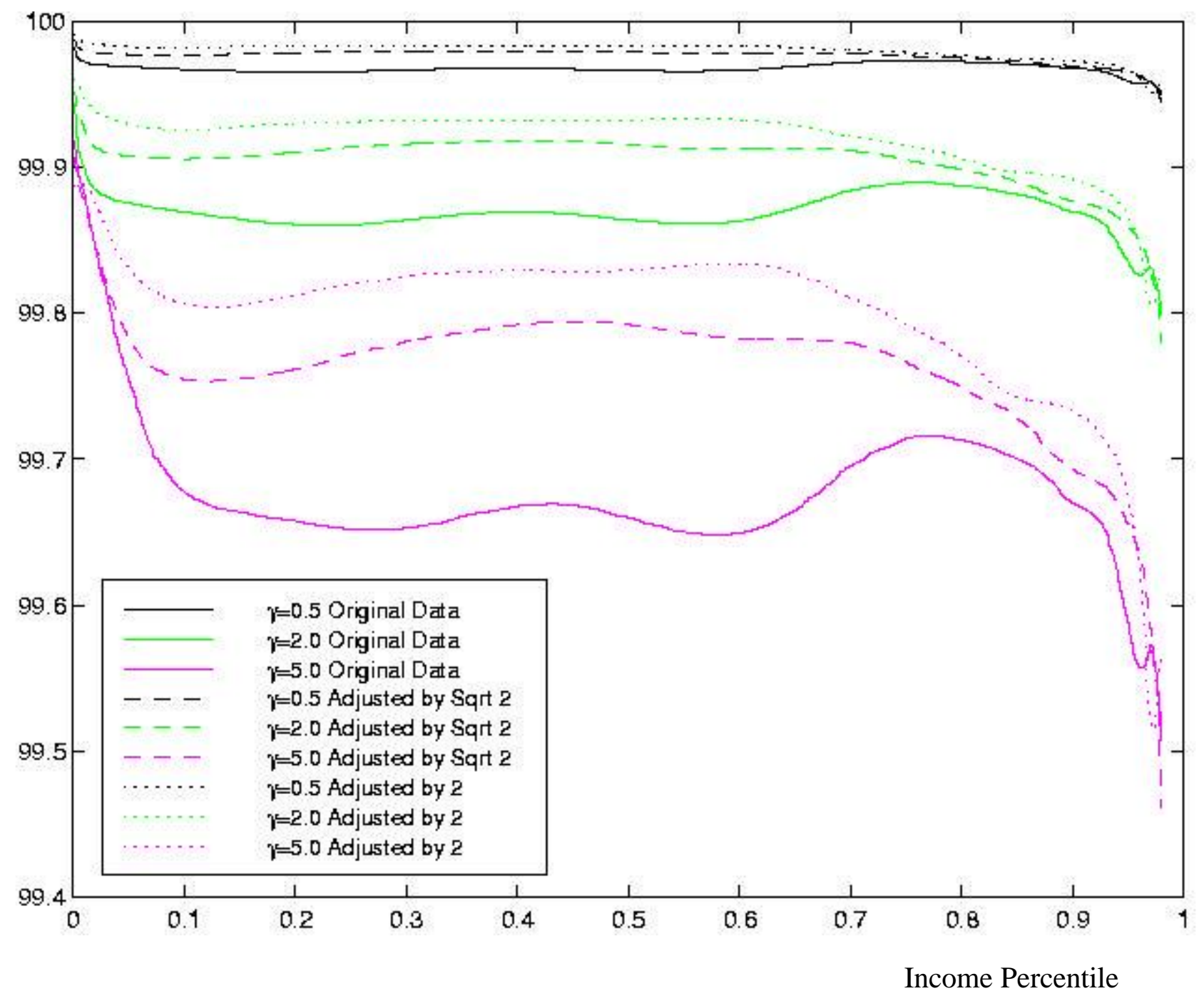


Figure 7. Index of Horizontal Equity: Individual Years, 1979-90

$(\gamma=2 ;$ Log Scaling $=.10)$

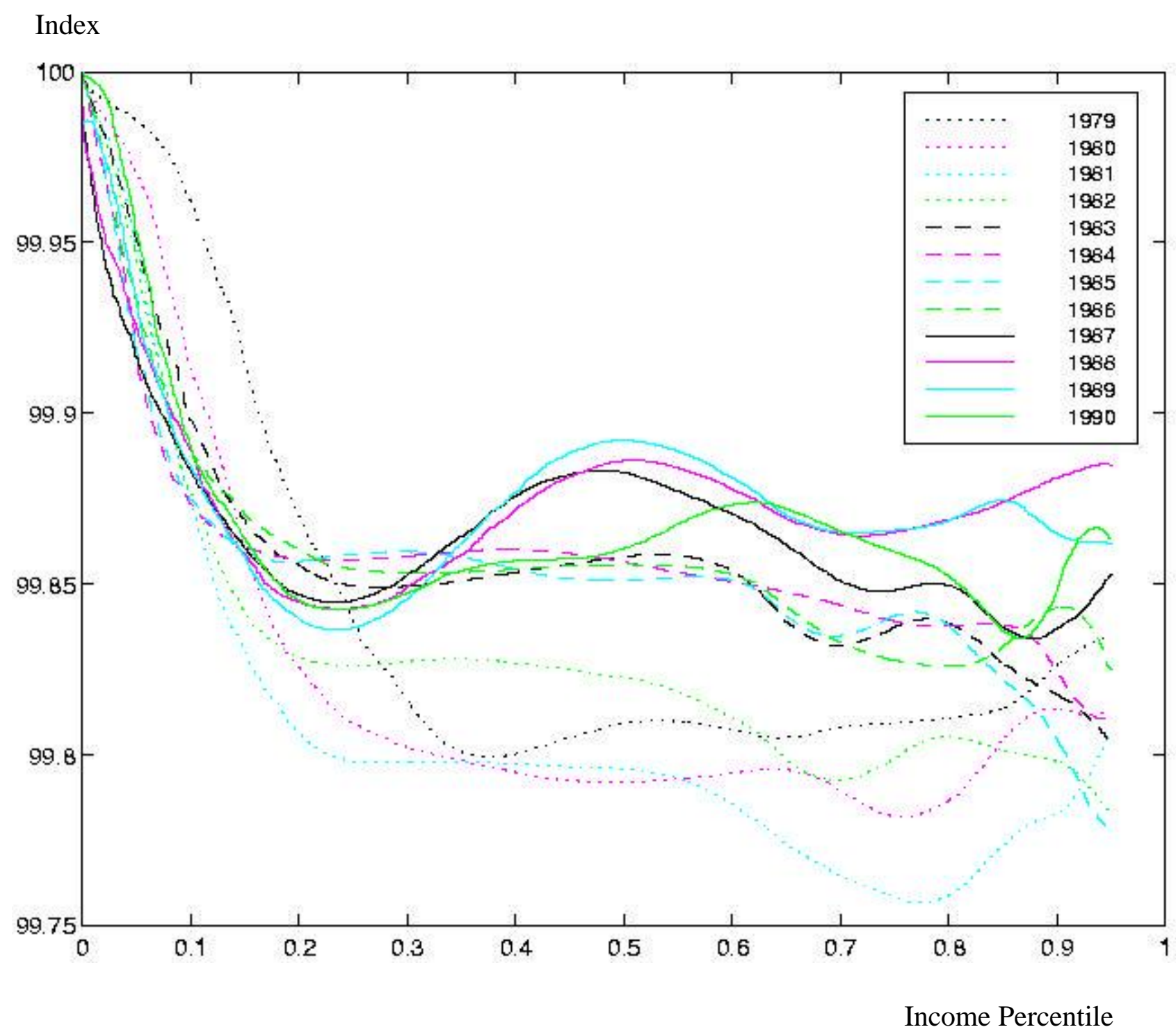


Figure 8. Index of Horizontal Equity: 1994

$(\gamma=.5,2 ;$ Log Scaling $=.10)$

Index

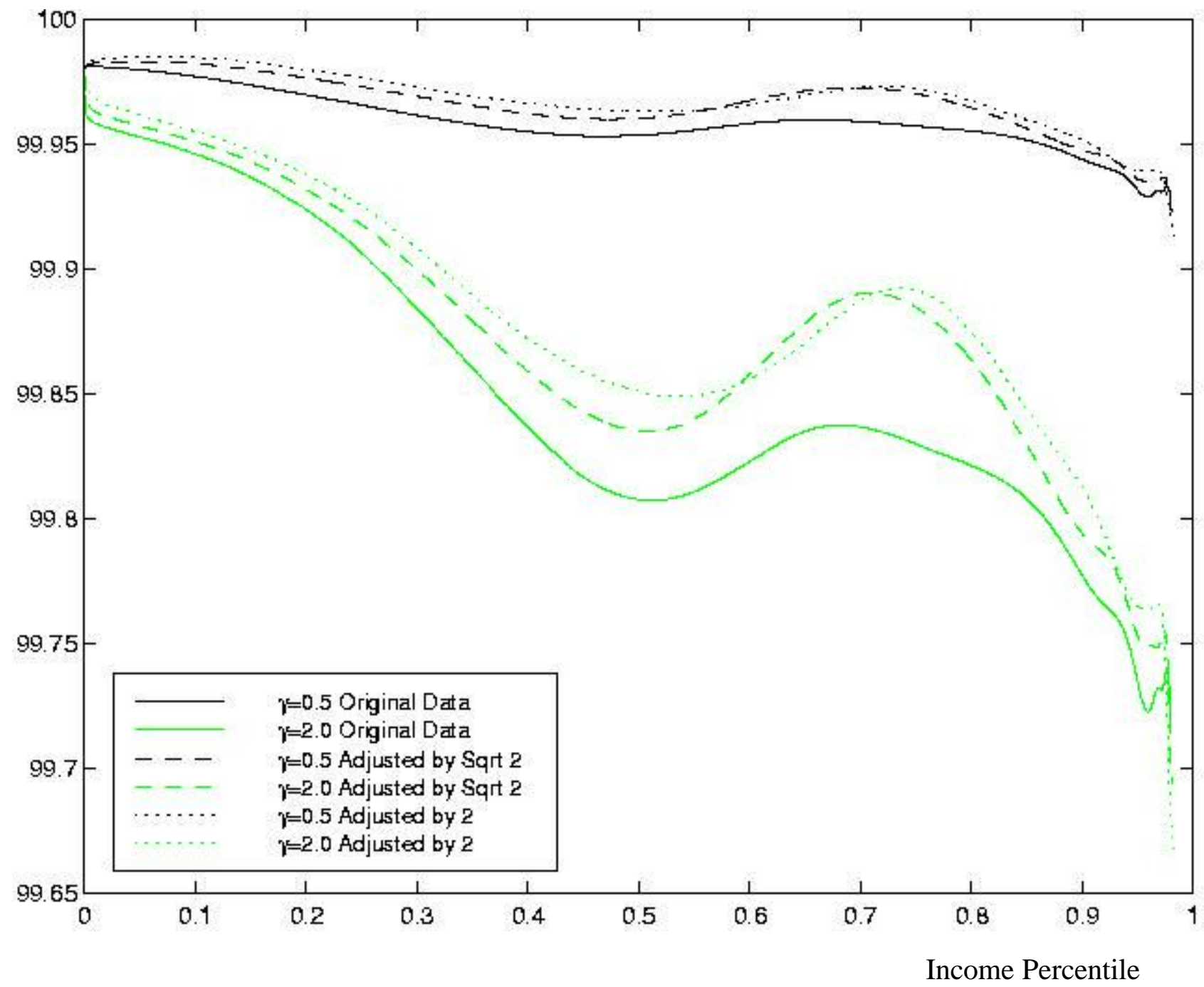


Figure 9. The Impact of Tax Reform, 1994: Equivalence Scale $=1$

$(\gamma=.5,2 ;$ Log Scaling $=.10)$

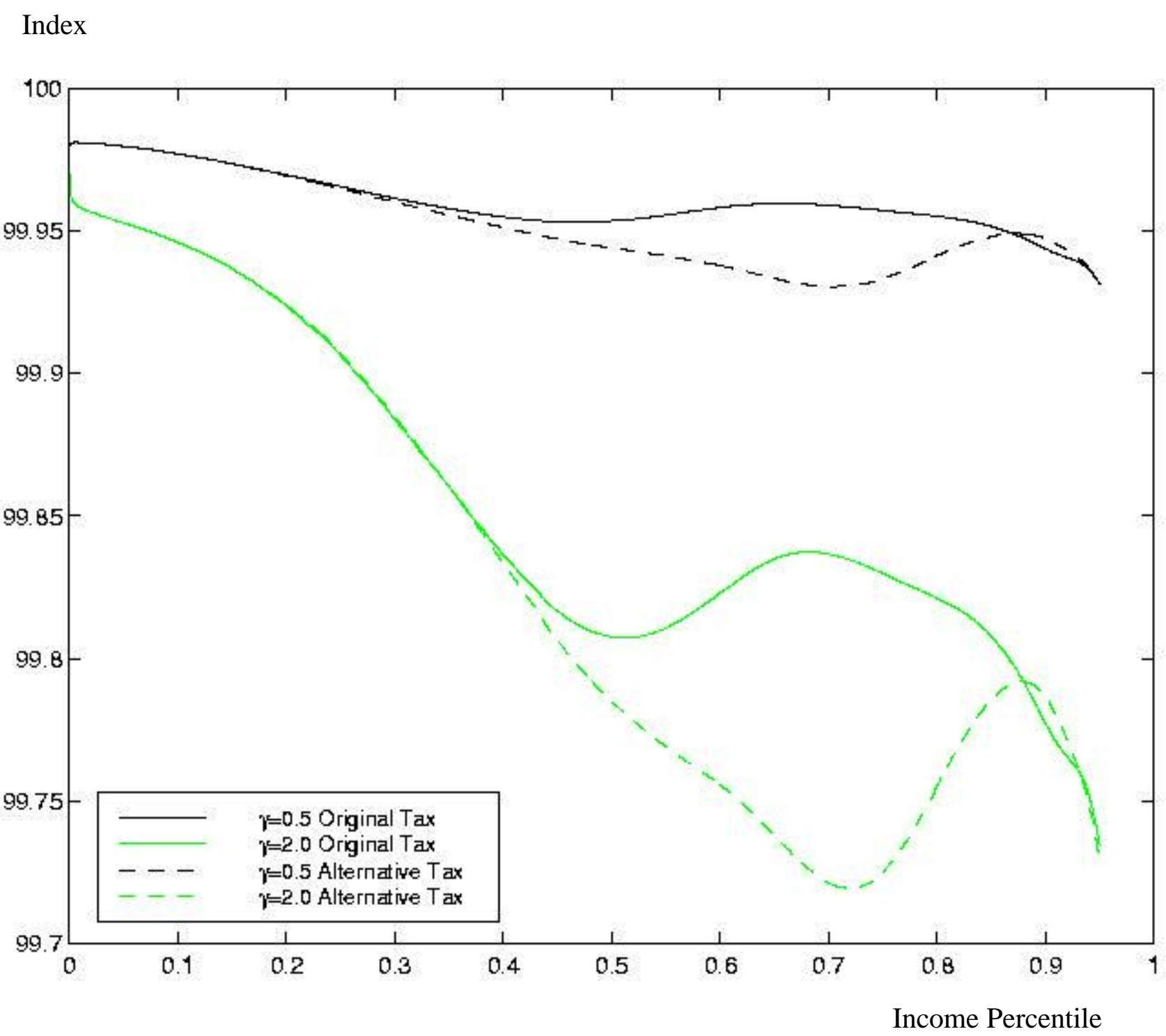


Figure 10. The Impact of Tax Reform, 1994: Equivalence Scale $=\sqrt{2}$

$$
(\gamma=.5,2 ; \text { Log Scaling }=.10)
$$

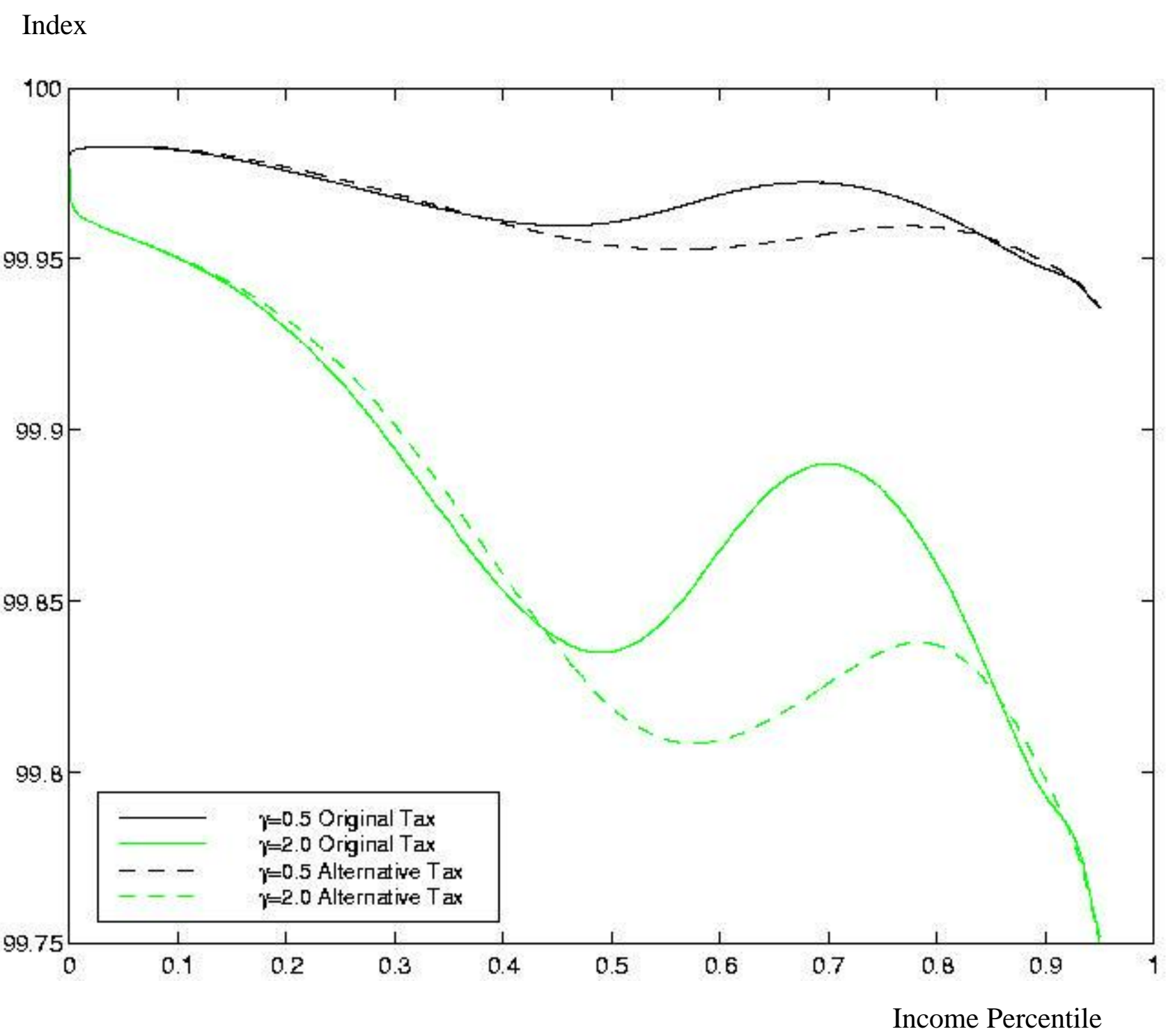


Figure 11. The Impact of Tax Reform, 1994: Equivalence Scale $=2$

$$
(\gamma=.5,2 ; \text { Log Scaling }=.10)
$$

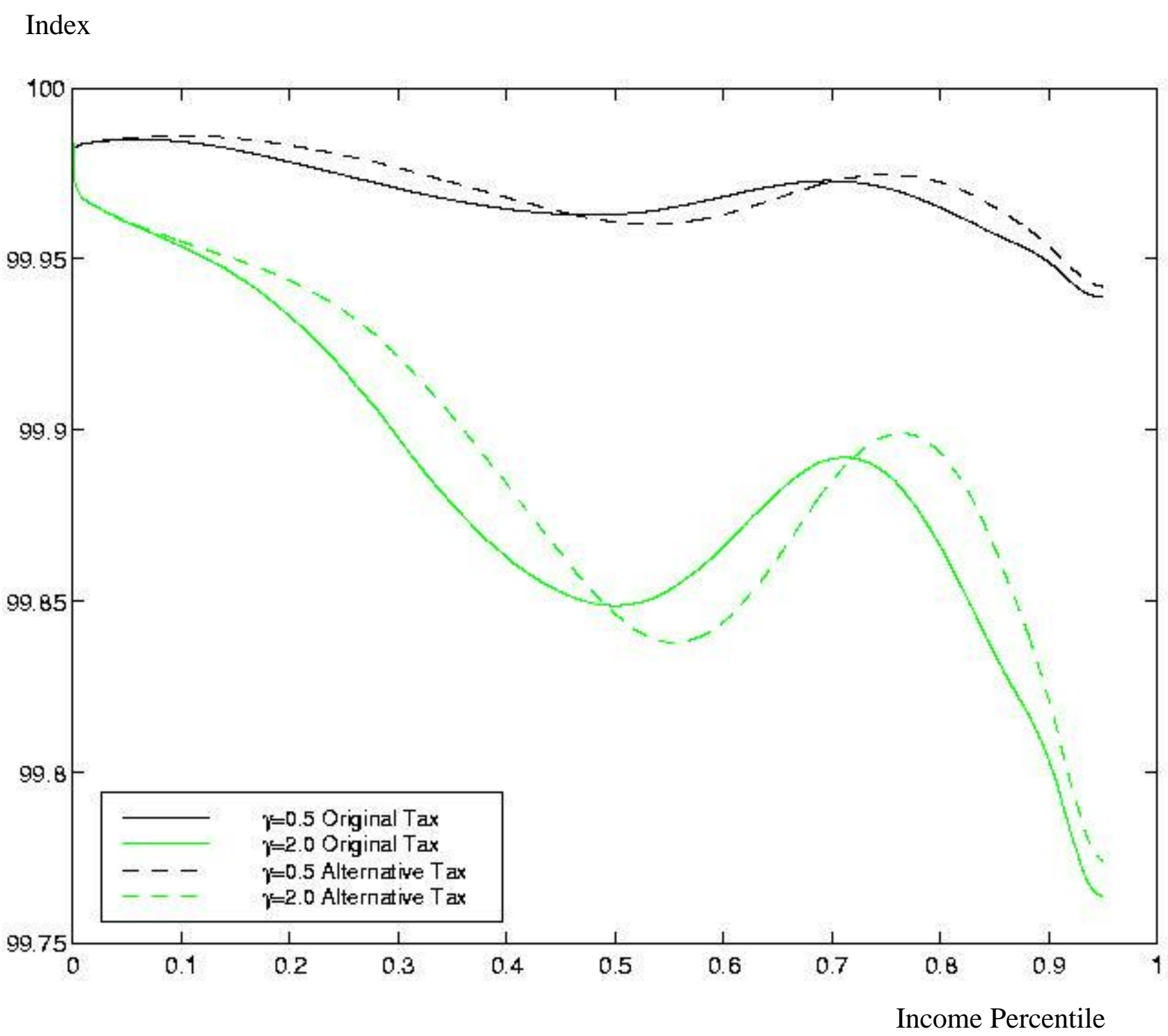


Figure 12. The Impact of Tax Reform, 1994: Equivalence Scale $=\sqrt{N}$

$$
(\gamma=.5,2 ; \log \text { Scaling }=.10)
$$

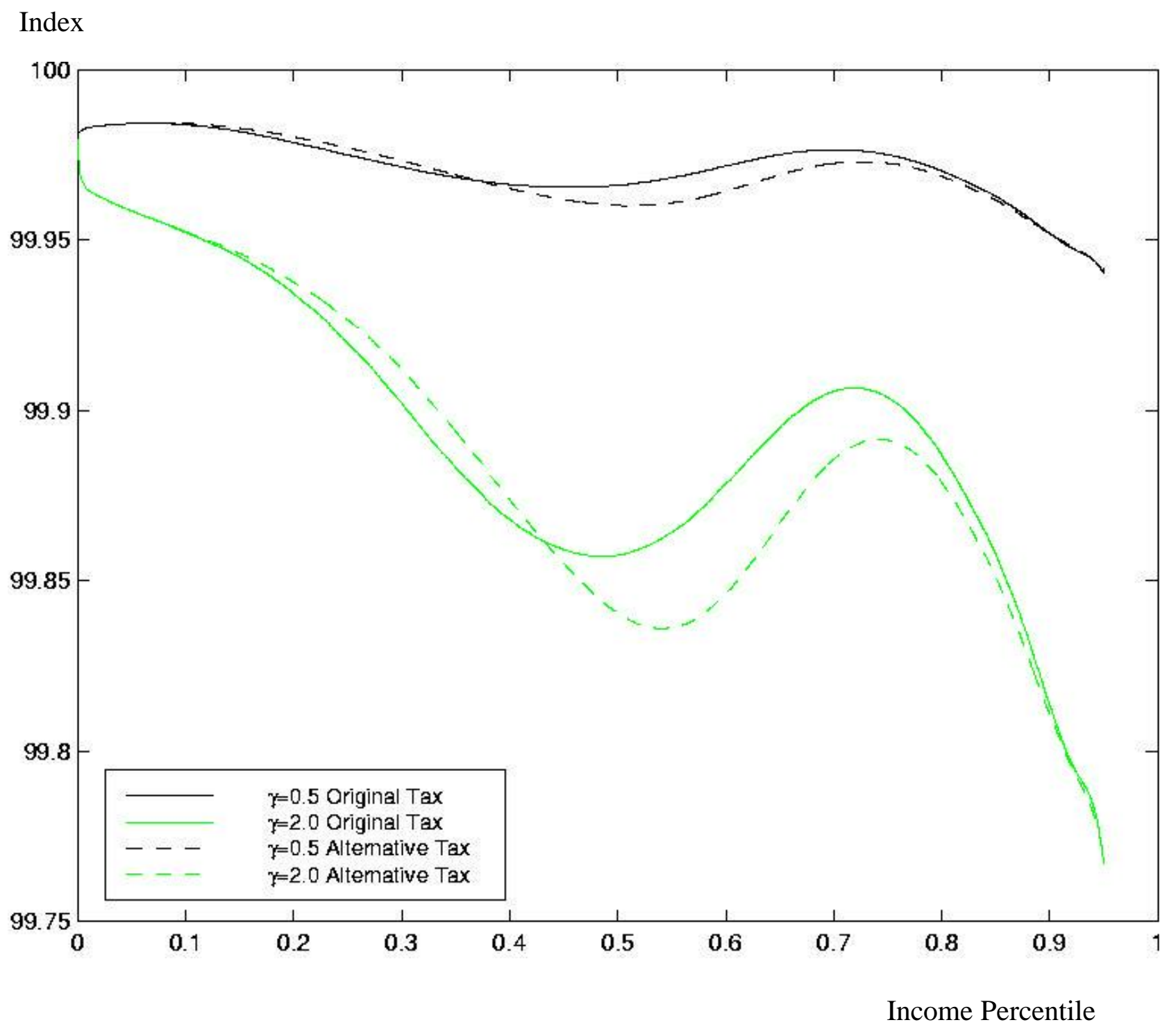


Figure 13. The Impact of Tax Reform, 1994: Equivalence Scale $=\mathbf{N}$

$(\gamma=.5,2 ;$ Log Scaling $=.10)$

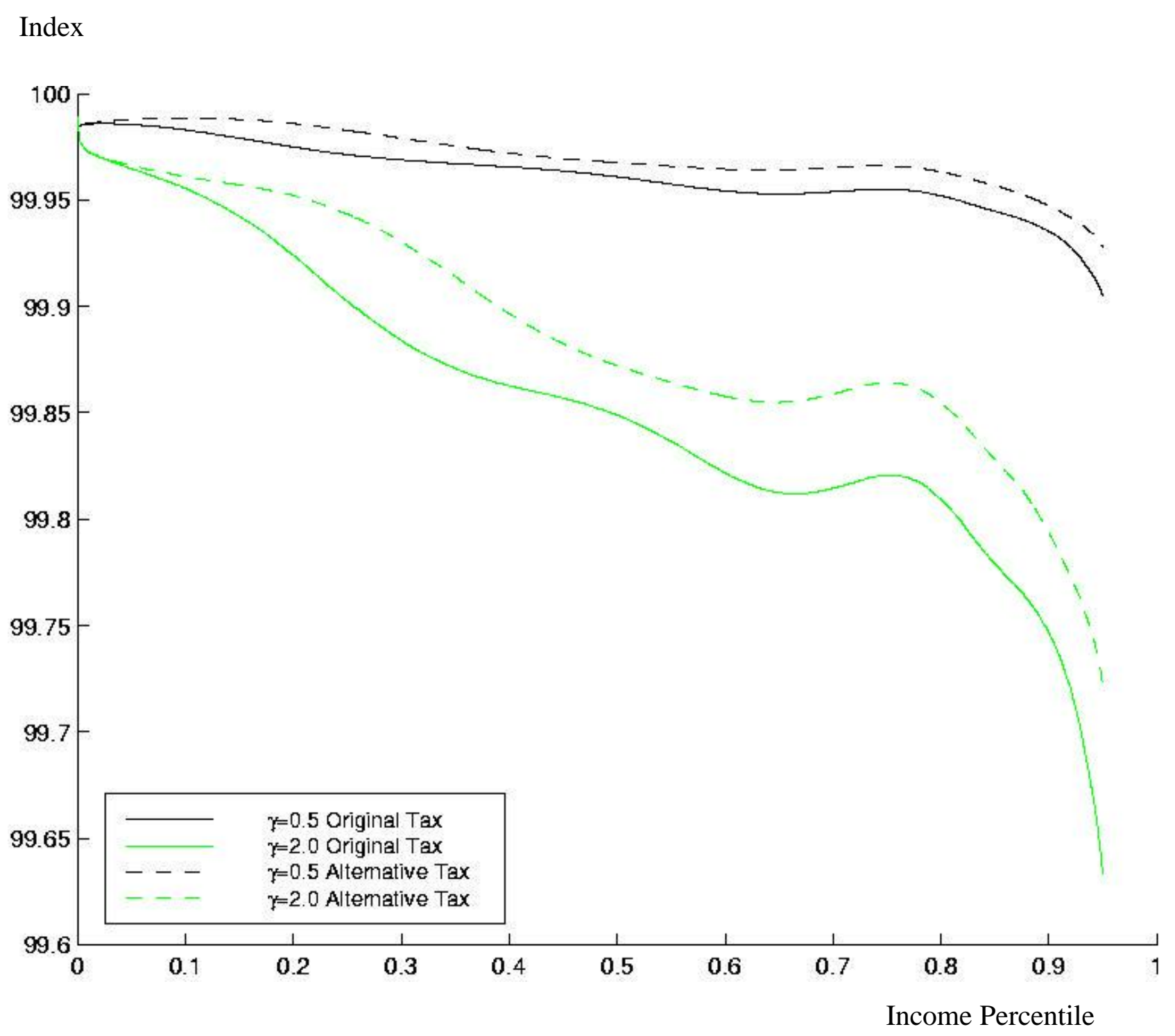

